\title{
Trends in Divorce Acceptance and Its Correlates across European Countries*
}

\author{
PETR FUČÍ K** \\ Masaryk University, Brno
}

\begin{abstract}
This study examines how the public acceptance of divorce has changed in European countries in recent decades. Taking advantage of the large-scale, comparative, and long-run measurement of value orientations in the European Values Study 1981-2017 it focuses on value change connected with divorce in a macro perspective. The article explores the acceptance of divorce in three aspects: 1) it measures and compares the trends in the acceptance of divorce in various European societies between 1981(1991) and 2017 and contrasts these trends with the data on divorce rates in these countries; (2) it explores the consistency/correlation between divorce attitudes and the affinitive value orientations associated in the broader set of values connected with the concept of the deinstitutionalisation of marriage; (3) it looks for the correlates of divorce acceptance and the changes in acceptance over time at the individual level (sex, education, cohort, family background, religiosity). Because of the descriptive nature of the research, no hypotheses are tested. The results show that divorce acceptance is rising over time in all EVS countries, and the acceptance is connected to divorce levels in given societies. Attitudes towards divorce form a consistent set of values together with other marriage deinstitutionalisation indicators. The acceptance of divorce correlates on an individual level with age, education, and religion, but surprisingly there is only weak difference between men and women.
\end{abstract}

Keywords: divorce, divorce acceptance, attitudes towards divorce, European Values Study, social norms

Sociologický časopis/Czech Sociological Review, 2020, Vol. 56, No. 6: 863-895

https://doi.org/10.13060/csr.2020.053

\footnotetext{
* Funding for this research was provided by the Czech Science Foundation - project number GA17-02022S 'Hodnotové změny v České republice z evropské a světové perspektivy' (Evropský výzkum hodnot/Světový výzkum hodnot 1991-2017).

** Direct all correspondence to: Petr Fučík, Faculty of Social Studies, Masaryk University, Joštova 10, 602 00, Brno, e-mail: fucik@fss.muni.cz.
}

(C) Sociologický ústav AV ČR, v. v. i., Praha 2020 


\section{Introduction}

Divorce is a phenomenon that has broad sociological relevance. The dynamics of the divorce rate the general societal trends of individualisation, secularisation, the transformation of intimacy, changing gender roles, and an increasing welfare state. These societal trends are partly the result of structural changes in the economic, political, and religious frameworks of societies. The structural transformations go hand in hand with the changing attitudes of social actors towards divorce. Sociological theory understands the fragility of postmodern partnerships as the flip side of the development of individual freedom of choice [Coontz 2007, 2015; Beck and Beck-Gernsheim 2005], the emphasis on romantic intimate relationships [Giddens 1993; Baumann 2003], the adherence to post-materialist values [Inglehart and Welzel 2005], and the decrease in the traditional stigmatisation of social action outside the rigorously constructed social institution of the family [Cherlin 2004; Smyth 2016]. All of these ideational changes represent important shifts in the value orientations that concern family life, resulting in changes in the acceptance of divorce.

Throughout this study we understand the acceptance of divorce in two senses: (1) individual acceptance, which is part of a personal value system and has causes, such as socialisation and individual experiences, and consequences, such as openness to one's own divorce or the divorces of others; and (2) societal acceptance, which is part of the cultural and value systems of society and is connected to the processes of the deinstitutionalisation of marriage and the family, the destigmatisation of non-traditional family behaviour, and changing gender roles. These concepts certainly overlap at the empirical level, and for our purposes, respecting the limits of the data, we indicate the latter one by the aggregating of the indicator of the former one.

Our research has three descriptive aims: (1) to measure and compare trends in the acceptance of divorce in various European societies in the last four decades and to confront these trends with the data on divorce rates in these countries; (2) to contextualise the acceptance of divorce by exploring how much the acceptance of divorce is aligned with certain affinitive value orientations relating to the deinstitutionalisation of marriage (acceptance of homosexuality, abortion, extramarital sex, and artificial insemination) and attitudes towards gender roles, and we also compare the consistency of these value sets among European countries; and (3) to search for the correlates of the acceptance of divorce and its changes over time at the individual level (sex, education, age, religion, and the prevalence of divorce in a given country). For these tasks we use data from five rounds of the European Values Study collected around the years 1981, 1990, 1999, 2008, and 2017. Our analysis will particularly focus on the the specific factors shaping divorce acceptance in the eastern part of Europe. The reason for this particular attention stems from number of divergences between the political, social, and demographic development of these regions during the 20th century. Even 30 years after the fall of the 'iron curtain' the traces of different social systems are still 
clearly visible, and we expect to find it also in the case of value orientations relating to family behaviour. Our motivations can be divided into theoretical and empirical ones. The most influential theoretical frames of the changes in family values and behaviour are mostly rooted in the interpretations of the development in the western part of Europe or the North American region (c.f. the theory of the second demographic transition [van de Kaa 1987, Lesthaege 20014], the marriage deinstitutionalisation thesis [Cherlin 2004, 2020; Smyth 2016], transformation of intimacy [Giddens 1993], and the risk/institutionalisation theory [Beck and Beck Gernsheim 2005], etc.) There is growing discussion about the applicability and the accuracy of these frameworks (particularly SDT) in the case of EasternEuropean societies [c.f. Sobotka 2008]. Historically these societies are part of the western cultural sphere, sharing the tradition of Christianity and secularisation, modernisation, and rationalisation, but one can argue either for the deep divergences in these processes compared to the western part of Europe. Divergences and convergences can also be discussed in reference to demographic indicators: the 'Hajnal line' was one of the first concepts to visualise these differences and it does not seem to have lost any of its relevancy even today [Hajnal 1965].

\section{The theoretical aspects of attitudes towards divorce}

In this part of the study I will present an overview of the basic theoretical approaches to understanding divorce acceptance that are of relevance here. The general concept of the social acceptance of divorce considers attitudes towards divorce to be part of the cultural and normative systems of a society that shape the norms about marriage, define the reasons for ending a marriage, and determine what sanctions and stigma the actors in a divorce will experience. Various authors have conceptualised the attitudes towards divorce as the source of a 'divorce culture' that has spread across different parts of society and has even influenced groups that are not direct actors in a divorce [Whitehead 1997; Hackstaff 1999; Yodanis 2005]. Simply speaking, divorce culture contrasts with marriage culture. 'A marriage culture includes the belief, assumption, and practice that marriage is a given and forever. A divorce culture, in comparison, is a set of beliefs and practices that define marriage as optional and conditional, with divorce being an option if the marriage does not work.' [Yodanis 2005: 645] Sociological research has repeatedly shown the relevance of this cultural shift for shaping the individual causes and consequences of divorce [Afifi et. al. 2013; Schovanec and Lee 2001; Toth and Kemmelmeier 2009].

For this reason, we understand attitudes towards divorce as an important part of the causal loops connected to the phenomenon of divorce. Without detailed knowledge about the attitudes towards divorce in a given society, it is possible to overlook the factors that influence, modify, and shape two pivotal elements of interest to scholars, professionals, and social services - the causes and consequences of divorce. General attitudes towards divorce shape the milieu in which people 
who may wish to seek a divorce make decisions act and can therefore significantly alter the legitimate causes and the expectable costs or consequences of divorce.

The research on divorce has mostly focused on the causes and consequences of divorce on the individual level. Both individual and societal causal relationships can be significantly modified by the societal milieu in which a divorce takes place. If a society is strictly opposed to divorce, the causes and consequences on the individual level would be influenced and shifted towards different means of social action. The individual decision to divorce can be influenced by a person's sense that the sanctions or stigma connected to divorce are low in a given context [Hiller and Recoules 2010; Furtado, Marcén and Sevilla 2011]. Conversely, the negative consequences of divorce can be exacerbated if there is a strong stigma attached to and negative attitudes towards divorce because of the higher cost of social action outside its institutionalised forms. This explanation of part of the negative consequences of divorce is labelled as the 'stigmatisation hypothesis' in the literature; evidence for this pattern in western European countries was provided by Kalmijn and Uunk [2009]. The stigmatisation hypothesis is especially important for debating the broader societal consequences of rising divorce rates: from a conventional point of view, the societal cumulation of the negative consequences of divorce rise in direct proportion to the rise of the incidence of divorce in the society. The insertion of a changing normative environment in this formula opens different perspectives. If a rise in divorce rates is accompanied by a rise in the acceptance of divorce and the destigmatisation of behaviours associated with being divorced (step-families, shared custody, single parenting, etc.), then it is possible to expect a decrease in the particular consequences of divorce that were previously caused by the higher costs of this social action within a stigmatising normative environment [Kalmijn and Uunk 2009]. Simply speaking, the stigmatisation hypothesis discusses the consequences of divorce that are caused by stigmatisation processes and not by the divorce process itself. It argues that these kinds of consequences decrease with the increased acceptance of divorce in society. The higher level of acceptance is here linked to the greater prevalence of divorce.

Some of the theoretical work on attitudes towards divorce focuses on the connection between the shifts in value orientations and divorce rates. Do the value changes follow the rise of divorce, or do the rising divorce rates reflect trends in value orientations? This question is continuously debated; it seems to resemble the 'chicken or the egg' dilemma. Even if the question cannot be resolved, it is useful to theoretically state the mechanisms that represent the two sides of the circular relationship.

On one side there is the role that experience plays in changing individual attitudes. Cherlin [1981] stated that the rise of divorce rates in the United States preceded the change in attitudes but also noted that changing attitudes increase divorce rates. According to Cherlin, the rising acceptance of divorce can be seen as a part of the deinstitutionalisation of the family. One of the hypothetical mechanisms behind this trend is the increasing experience with divorce in the social environment - the more divorce there are in a person's social network, the more 
that person is confronted with the possibility of considering that it is the result of an intelligible and justifiable decision.

On the other side, there is a notion that the normative environment affects the repertoires of social action and that value change precedes demographic behaviour. As the stigma and sanctions connected to divorce weaken, the costs of the decision to divorce decrease and more people decide to act on their wishes to get divorced. This has also been identified as a factor in the theory of the second demographic transition, the authors of which argue that post-materialistic values and the importance of self-expression changed family behaviour in the last third of 20th century [van de Kaa 1987; Inglehart and Baker 2000; Lesthaege 2014]. Particularly interesting and relevant for this study is the discussion about how applicable the second demographic transition (SDT) framework is to eastern European, post-communist societies [Sobotka 2008].

The changing societal attitudes towards divorce do not have gender-neutral consequences, nor does divorce itself. Hackstaff argued that a divorce culture strengthens the position of women in negotiations about family life, because the availability of divorce forces both partners to consider the demands of the other. Her reasoning is based on qualitative research on successive cohorts of American married couples [Hackstaff 1999]. Inspired by Hackstaff, Yodanis [2005] tested the hypothesis that the availability of divorce enhances the position of women in relationships, known as the enhanced equality hypothesis. Her results, based on International Social Survey Programme (ISSP) data from 22 countries, show that 'in countries where divorce is accepted and practiced, the distribution of work between women and men in marriage is more equal' [Yodanis 2005: 644]. At the same time, it is necessary to be very cautious about causal inferences because the relationships can be stated in either direction or even in a circular manner.

\section{Research on the societal acceptance of divorce}

Now we will focus on empirical studies that have explored the trends in divorce acceptance and the correlates of divorce acceptance at the individual and societal level. During the second half of the 20th century, divorce in western societies 'was being removed from the realm of the morally absolute with people increasingly willing to consider the circumstances of the specific situation instead of imposing an absolute rule against divorce' [Thornton 1985: 857]. A similar situation, at least in terms of divorce rates, can be seen in the eastern part of Europe. This would suggest that the change in divorce rates and the acceptance of divorce are largely rooted in modernity itself, regardless of the particular and temporal political circumstances [cf. Amato and Irving 2005]. The studies based on survey data show significant shifts in the public acceptance of divorce in the later 20th century in various countries [Thornton and Young-DeMarco 2001].

Gerstel [1987] suggested that despite changing public attitudes towards divorce, the stigmatisation has only in a limited sense disappeared. There is a gap 
between the decline in public disapproval of divorce and the continuing disapproval of divorced individuals. According to her qualitative interviews with 52 women and 52 men, people who have divorced suffer informal relational sanctions [Gerstel 1987: 173]. Almost thirty years later, Konstam et al. [2016] conducted another set of interviews and found similar stigmatisation experiences among young adult women who were divorced. Although the studies show that there is still a stigma attached to divorce, it is important to take into account its unprecedented dynamics over the 20th century. In many contexts, divorce was simply unthinkable even fifty years ago. The gendered nature of the stigma is also vanishing together with the decline of the norms attached to gender-specific roles in marriage and in the maintenance of the intimate relationships [Emery 2013].

Empirical research on attitudes towards divorce focuses mostly on the social groups that are considered to be at risk through the personal experience of marriage dissolution. The logic behind this focus is to understand attitudes as the predictors of divorce. The research has shown that the individual factors affecting attitudes towards divorce are significantly structured by religion and gender [Kapinus and Flowers 2008], age [Brown and Wright 2019], and education [Martin and Parshar 2006].

Family background, especially the experience of a parental divorce, is a similarly significant factor affecting divorce attitudes [Amato 1988, Amato \& Booth 1991, Sieben \& Verbakel 2013]. This link represents the part of the causal chain between parental divorce and the higher divorce risks of their offspring called the 'divorce cycle' [Wolfinger 2005]. Sieben and Verbakel [2013] used some of the same data (EVS 2008) to examine the influence of divorce experiences in three social contexts - parental divorce, divorce in the kin network, and the level of divorce at the national level. Their results show that divorce experiences in closer social contexts shape pro-divorce attitudes, but the broader national level of divorce does not have an effect [Sieben and Verbakel 2013: 1186].

Based on the theoretical arguments and the empirical findings concerning various aspects of the concept of divorce acceptance, I have formulated four hypotheses to test in this analysis:

H1 Divorce acceptance will be rising in all European societies, but the dynamic of the rise will be different in different geographical contexts. The expectation here that divorce acceptance will rise is based on theoretical arguments about the decreasing stigmatisation of divorce that are shared by various conceptual frameworks such as the second demographic transition theory [van de Kaa 1987; Lesthaege 20014], the family deinstitutionalisation thesis [Cherlin 2004, 2020; Smyth 2016], the transformation of intimacy [Giddens 1993], and the risk/institutionalisation theory [Beck and Beck Gernsheim 2005], etc. In the second part of this hypothesis, the focus is mainly on the differences between countries with a shared post-Soviet and postcommunist historical experience. Although I will compare data from all countries available in the EVS data, I believe that insufficient attention has been paid to 
the specific geographical and historical context of this region. The expectation of distinctions is based on Sobotka's [2008] arguments about the different nature of SDT within central and eastern Europe.

H2 Divorce acceptance at the societal level will be consistent with the prevalence of divorce in a given society. Here the crude divorce rate will be used as an indicator of divorce prevalence, and the relationship between the two will be measured on the aggregated level. This assumption is derived from Cherlin's thesis about the circular relationship between the more widespread experience of divorce within a societal context and attitudes towards divorce.

H3 Divorce acceptance is a part of a broader consistent set of values concerning family deinstitutionalisation. This hypothesis will be tested by focusing on the consistency of divorce acceptance with attitudes towards homosexuality, abortion, casual sex, in-vitro fertilisation (IVF), and gender attitudes. This hypothesis is designed to test another aspect shared by various theoretical frameworks of SDT, deinstitutionalisation, and individualisation/destigmatisation: the consistency of the shift towards the acceptance of formerly stigmatised forms of social action connected to the institution of the family (particularly partnership and parenthood). If this is true, we should be able to identify a high degree of similarity between the trends in these value orientations in a given society. Gender attitudes are expected to be relevant in light of the theoretically and empirically demonstrated relationship between the historical trends in gender equality and the possibility of divorce [cf. Becker 1981; Gerstel 1988; Cooke et. al. 2013].

H4 Individual divorce acceptance will be affected by gender, age, education, religion, and the divorce rate in a country. Only the few basic and theoretically demonstrated individual correlates that are available across all waves of the EVS survey are used in the analysis here. Although many other factors are theoretically relevant (at least the experience of parental divorce would be very beneficial), they are unavailable in a consistent way for the whole time series of the EVS survey. The presumed relevance of gender for divorce attitudes is based on the broad set of empirically founded mechanisms that are partially rooted in the historical dynamics of the transformation of gender roles and are partially based on the different consequences of divorce for men and women. Given that the historical dynamics of divorce acceptance is the subject of the first hypothesis, the examination of the age differences allows us to deepen the understanding of temporal dynamics by distinguishing between age effect and period effect. The relevance of age is given by the different socialisation of various cohorts and different life experiences, which could alter value orientations. Controlling for the educational gradient of divorce attitudes is necessary from at least two points of view. First, it will provide us with indirect information about the social stratification of divorce acceptance, which, according to the SDT and the individualisation theory, is the domain of the more educated segments of society. Second, the educational 
gradient of divorce attitudes can be contrasted with the educational gradient of divorce itself in given societies, which is outside the scope of this paper, but it is the part of the puzzle of the stratification of marital instability [c.f. Härkönen and Dronkers 2006; Matysiak, Styrc and Vignoli 2014], Although the obligatory effect of religious doctrine on family behaviour falls under secularisation processes, the importance of individual religious identity as a factor that shapes value orientations is growing. In contrast to the relative homogeneity of traditional religious societies, secularisation introduces heterogeneity and sharper distinctions between religious and non-religious people. Given that the family is one of the one of the main issues at the centre of these cleavages, I expect that divorce attitudes will differ according to individual religiosity [Wilkins 2016]. The last hypothesised correlate of divorce acceptance is the country's divorce rate. Here the logic is different from the individual-level factors discussed above, because I combine the aggregated level indicator with the individual level divorce acceptance. The reason for this combination is to provide another way of testing the second hypothesis that is formulated strictly at the aggregate level. Examining the relationship at this level will to enhance the interpretation of the causal links between the general societal experience with divorce and individual divorce attitudes.

\section{Data and methods}

To analyse trends in the social acceptance of divorce, I used data from the European Values Study (EVS), one of the largest cross-national, repeated, crosssectional survey research programmes in the world. Five rounds are currently available: 1981, 1990, 1999, 2008, and 2017. The number of countries involved in the survey rose from 16 in 1981 to 46 in 2008. The survey in each country consists of a representative random sample of the adult population (18+). The countrylevel sample size ranges between 304 observations (Northern Ireland, 1981) and 5407 observations (Germany, 2017). The average sample size increased from 1211 cases in 1981 to 1879 cases in 2017. The total number of observations available in the five integrated international data files is 221365 . Detailed information about the methodology and sampling procedures is available at the website of the project and through the documentation at the GESIS data archive [Gadeshi et.al. 2015]. The data from the first round of EVS is rather specific, because at that time only 14 countries from the western part of Europe along with the US and Canada participated in the survey, which selectively limits the possibility of a time series comparison. ${ }^{1}$ The 2017 integrated dataset was moreover incomplete when this article was being written (fall 2019); when the dataset is completed it will contain other countries and more observations. Despite these facts, I decided to use even these rounds of the EVS to offer the longest possible comparison, where the data

\footnotetext{
1 The data for the US and Canada were dropped from this analysis; although a comparison with Europe could be beneficial, it would be possible only for the 1981 wave.
} 
were available, but it should be noted that most of the time comparisons make sense in the period between 1990 and 2017 (2008). Similarly, we decided to use as many country data as possible to get at least one measurement of divorce acceptance in surveyed countries. Therefore, I did not exclude countries that participated in only one round of the EVS, because aside from the time dimension of the comparison I am also interested in geographical differences.

As the core indicator of the social acceptance of divorce, we used the item that focused on divorce within the set of questions measuring the justification of different kinds of social action. The set was introduced by the question: Please tell me for each of the following statements whether you think it can always be justified, never be justified, or something in between. The responses were coded on a 10-point scale, where $1=$ never and $10=$ always. The logic of the battery, the initial question, and the scale of the response remained unchanged in all waves of the EVS, but there is slight variability in the number of items included in the battery. The item divorce was primarily used in the analysis as it was present in all EVS waves. To analyse consistency with the different dimensions of the destigmatisation of nontraditional family behaviour, the items homosexuality and abortion were also used, as they are present in the master questionnaire, along with the items married men/ women having an affair and artificial insemination / IVF, which are present in the main questionnaire in only some EVS rounds (since 1999 and 2008, respectively). Although the lexical meaning of justification and acceptance is different, we use answers to the given questions as an indicator of acceptance. We believe that the more justifications (for a behaviour that) are available and tolerable in a society, the more accepted the behaviour is. When the answers shift towards the 'always' side of the scale, the justifications turn to be universal, because the given social action is 'always' justified. Conversely, when the answers tend to be on the 'never' side of the scale, no justification is tolerable, therefore the given action is not accepted. This is the reason I use the term 'social acceptance' of divorce instead of justification.

Most of the analysis used an exploratory strategy that drew on basic descriptive statistics. I have decided to provide and present more descriptive results here at the expense of reducing the strategy of regression model testing to a minimum. This decision was primarily motivated by an interest in thoroughly describing the trends and differences in divorce acceptance in all the countries surveyed and ensuring the simplicity and comprehensiveness of the analysis. In practical terms the decision is influenced by two facts: (1) it is difficult to find an identical set of explanatory variables for all five EVS waves, therefore the available indicators in each round were used instead to map their effect on divorce acceptance even if they are not available in all survey years; and (2) the modelling strategy always has to focus on the relatively narrow goal set out by a specific hypothesis and by the logic of the model building. In contrast to this strategy, the five EVS waves provide rather complex sets of relevant factors affecting divorce acceptance in various conceptual connections and complex relational logic. Descriptive statistics are used in the analysis in order to provide the reader with information 
about the various factors of divorce acceptance at the country-level, while the regression models summarise information at the level of clusters of countries. The clustering could formally be done using a cluster analysis, but here an informal interpretation of the results of the exploratory descriptive statistics and the set of regression models is offered instead.

\section{General societal trends in the rising acceptance of divorce and the connection with rising divorce rates}

The basic descriptive results comparing the mean values ${ }^{2}$ on the 10-point scales of the social acceptance of divorce clearly show that divorce acceptance has been increasing significantly in the last three or four decades in all the countries surveyed in which time series data are available (see Figure 1). There are only a few exceptions: Albania, Georgia, Latvia, Romania, Turkey, and Ukraine (not counting the countries that have only one point in time). Comparing the data on the social acceptance of divorce shows the lowest acceptance in Malta and Kosovo, which are the outliers compared to the other countries. ${ }^{3}$ There are relatively lower levels of divorce acceptance in the eastern part of Europe, particularly in the postSoviet countries, and also specifically in Ireland and Northern Ireland, Cyprus, and Northern Cyprus - countries in which religious cleavages are extremely relevant. The level of divorce acceptance is moderate in the post-communist countries and is relatively high in the rest of the Europe, with the highest levels traditionally found in the northern countries.

Sorting the countries according to the absolute difference between the initial and final values yields similar results: there are three clusters of countries. ${ }^{4}$

\footnotetext{
2 The distribution of the variable is far from normal - there are peaks at the values 1,5 , and 10 and lows between them. What changes over time is the proportion of responses in the corner positions and in the middle. In 1981, the most frequent categories were the middle position and the corner value of 1 (never). In 2017, the modal value is 10 (always), with a smaller peak again at the value 5 . For this reason, the mean values cannot be understood as a good measure of a central tendency (the standard deviation is too high), but its use was considered in order to enable an instant comparison. The mean values are useful for measuring changes in the distribution and mostly illustrate the proportion of the abovementioned peaks, but it would be a mistake to take them as indicating the attitude held by the majority of the given (sub)population. Inferential statistics are not used for any of the descriptive results. In relatively large samples significance testing makes it possible to reject the null hypothesis even in cases where there are tiny substantial differences. Simply put, if the difference in the sample is substantially significant, it is well above the critical value of the significance test.

${ }^{3}$ Divorce has been legal in Malta since 2011. The change in the law was initiated by a divorce referendum in which $53 \%$ of voters approved the proposal to allow divorce.

${ }^{4}$ Only the countries that participated in at least three waves of the EVS are used in this analysis.
} 


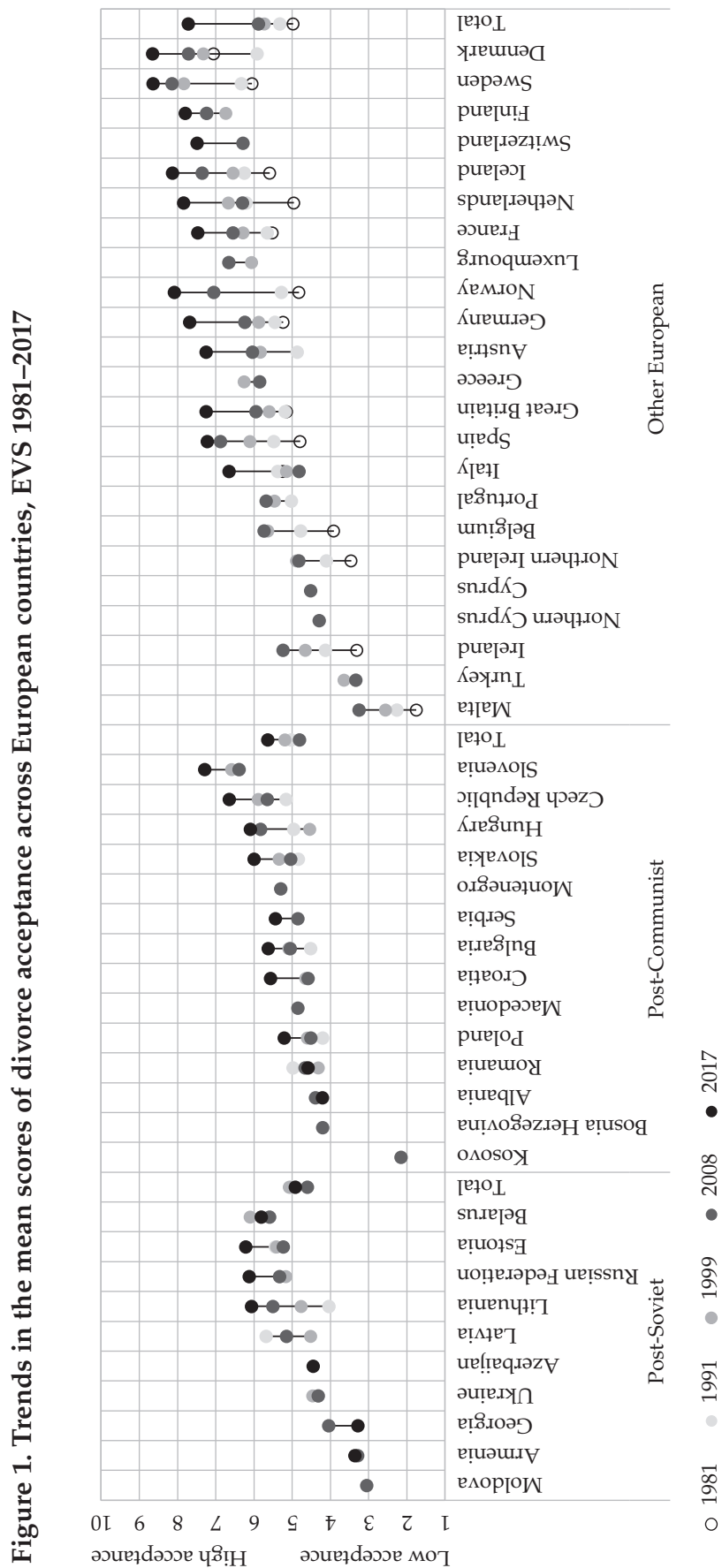


The first is the cluster of post-Soviet societies (with the exception of Lithuania), where the shift in the social acceptance of divorce is relatively small (mostly about a 1-point difference on the 10-point scale). ${ }^{5}$ The second cluster represents the countries where the change is modest or average (up to a 2-point difference on the 10-point scale) - mostly the post-communist societies. The countries included in the third cluster experienced the most dramatic changes in the social acceptance of divorce (up to a 2.8-point difference). This cluster includes mostly the countries of western Europe and relatively the biggest increase in acceptance is among the northern countries or the societies predominantly characterised by a Protestant religion. The sharpest rise in both the second and third clusters is seen between the 2008 and 2017 rounds. This is particularly interesting in the light of the fact that in most countries divorce rates stagnated or even dropped after 2010 [Eurostat 2020a].

The crude divorce rate was used in the analysis to determine the relationship between the social acceptance of divorce and the incidence of divorce at the aggregate level. ${ }^{6}$ At the initial stage of the analysis, we measured the correlation between divorce acceptance and the crude divorce rate within the set of countries for each EVS wave. ${ }^{7}$ In the first wave, data are available for only eleven countries and the R-squared reaches 0.230 . In 1990, several new countries joined the survey and the R-squared dropped to 0.061. A similar situation was seen in the next waves, where the correlation is relatively low. The low correlation between divorce acceptance and divorce rates on the aggregate level is caused by the heterogeneity among the clusters of countries. A thorough analysis of the scatterplot of the countries reveals the former post-Soviet countries ${ }^{8}$ systematically form a cluster that is remote from the general linear relationship because of the relatively high divorce rates and relatively lower divorce acceptance in these countries. Conversely, in western and northern European countries, there is a clearly visible relationship between higher divorce rates and higher divorce acceptance. Separating the post-Soviet countries from the file, the R-squared measured in 2008 increases to 0.19 and the R-squared measured in 2017 increases to 0.37. Another pattern is clearly visible on the scatterplot in 2008 , when the participation of post-

\footnotetext{
5 This is partly due to the fact, that the post-Soviet countries did not participate in as many waves of the EVS survey, but if the relative shifts between individual rounds are compared, the trends in these societies remain the least dynamic ones.

${ }^{6}$ The crude divorce rate denotes the proportion of divorces per 1000 members of a population in a given year. As such, it indicates the prevalence of divorce in a society and reflects the possibility of experiencing divorce in different social contexts. In contrast to a similar analysis by Sieben and Verbakel [2013], the decision was made not to use the marriage-todivorce ratio here (divorces per 100 marriages in a given year) because this indicator can be significantly distorted by trends in marriage rates.

7 Eurostat data for 1981, 1990, 1999, 2008, and 2017 are used. For some countries in some years the crude divorce rate is not available, in which case they were dropped from the analysis for the given year [Eurostat 2020a].

${ }^{8}$ Belarus, Estonia, Georgia, Moldova, Lithuania, and the Russian Federation.
} 
Figure 2. Association between divorce rate and divorce acceptance in $2008^{*}$

Post-Soviet countries

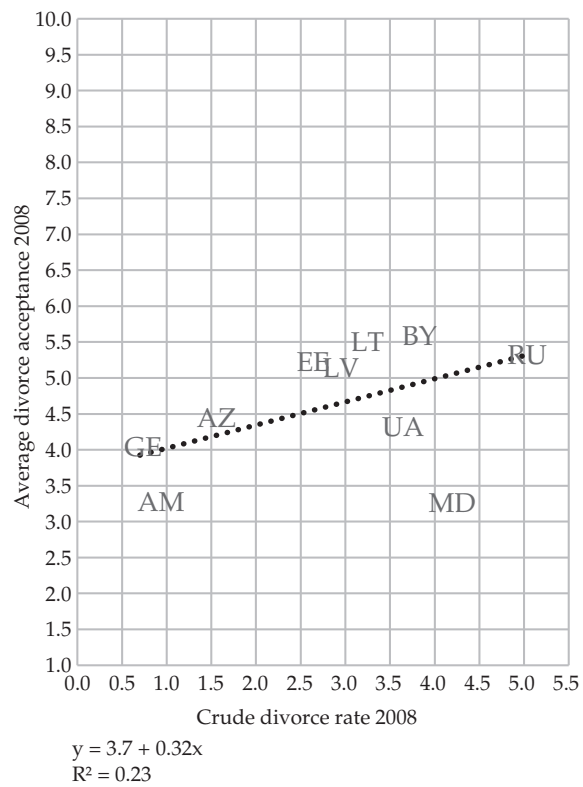

Other European countries

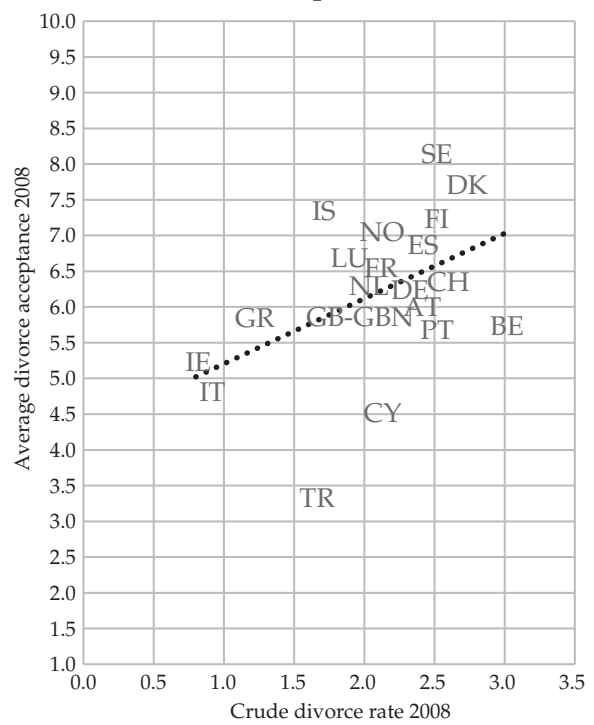

$\mathrm{y}=4.3+0.91 \mathrm{x}$

$\mathrm{R}^{2}=0.22$
Post-communist countries

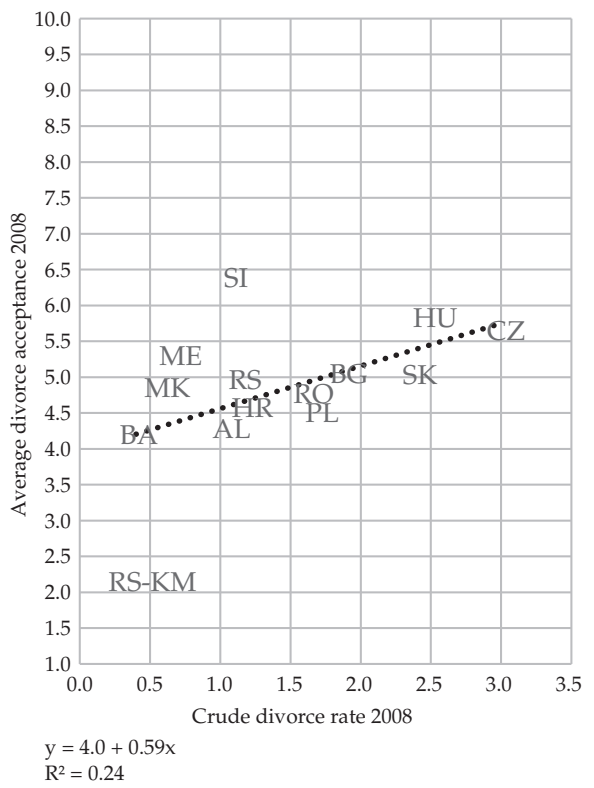

$\mathrm{y}=4.0+0.59 x$
* note the different scale of crude divorce rate for the post-Soviet figure 
Soviet and post-communist countries peaked (see Figure 2). Inserting a regression line on the aggregated data, the countries of the former western (capitalist) part of Europe in most cases lie above the line ${ }^{9}$ and the post-communist countries are below the line. ${ }^{10}$ This is because the acceptance of divorce is generally lower in the post-communist countries, but the linear relationship between acceptance and prevalence is very similar to the rest of the Europe.

The crude divorce rate rose until 2008 in all the surveyed countries, as did the acceptance of divorce; there is an unsurprising observable correlation between these two indicators. The clustering of the shape of this relationship is more interesting and it provides the next argument for distinguishing two groups of countries within the former eastern bloc. Like in the previous analysis we see three clusters: (1) post-Soviet countries, where the social acceptance of divorce is lowest and divorce rates are relatively high - here the connection between the divorce rate and the divorce acceptance is the weakest; (2) post-communist countries, where the acceptance of divorce is relatively lower than in western Europe, but the contingency between the rise of divorce and its acceptance is clearly visible and its correlation is moderate; and (3) the countries of the former western part of Europe, where the acceptance of divorce is the highest and the relationship between acceptance and the divorce rate is affected by whether there is a Catholic or Protestant tradition in the country. It is also of course possible to observe others forms of heterogeneity within the clusters, but we believe this is clearly understandable with respect to the characteristics of given outlier countries compared to the rest of the cluster.

These results support the argument that the mutual relationship between attitudes and divorce rates is significant, contradicting the conclusion of Sieben and Verbakel [2013] that experience with divorce at the societal level has no effect. These correlations on the aggregated data are still far from an estimation of an individual effect of the social context of divorce prevalence on individual attitudes towards divorce. Therefore, national-level divorce rates were used as a contextual variable in the regression models estimating the factors shaping individual divorce acceptance (see the section 'Summarising divorce acceptance correlates in the regression model').

\section{Searching for value clusters - divorce, other non-traditional types of social action, and gender roles}

To examine the consistency between attitudes towards divorce and other attitudes that could lead to the stigmatisation of non-traditional family patterns, another four indicators from the battery of items measuring the acceptance of various types of behaviour were examined: homosexuality, abortion, casual sex, and arti-

\footnotetext{
${ }^{9}$ With the exception of Belgium in 2008.

${ }^{10}$ With the exception of Slovenia in 2008 and 2017.
} 
ficial insemination (or IVF). All of these items are tightly correlated, representing a presumed value cluster (see Table 1). Considering the internal structure of this set of attitudes, the strongest is the association between the acceptance of divorce and the acceptance of abortion (total $\mathrm{R}$ is about 0.7 ). The acceptance of divorce also correlates strongly with the acceptance of homosexuality. There is a relatively weaker correlation between this attitude and the acceptance of casual sex (but the $\mathrm{R}$ is still above 0.5) and the weakest correlation is with the acceptance of artificial insemination (total $\mathrm{R}$ is 0.4 ). However, our interest is in the different levels of correlation between the acceptance of divorce and other attitudes within countries across the five waves of the EVS. The relatively high correlations with the other attitudes remain stable over the almost forty years of the survey. The consistency of the value clusters is relatively weaker in eastern European countries than in western Europe, particularly in the case of the acceptance of homosexuality, the consistency of which remains relatively weak over the three decades in the postSoviet countries but rises over time in the post-communist countries.

Given that the work of maintaining a relationship and a stronger obligation to stay in a marriage even if it is unsatisfactory have been traditionally required of women, attitudes towards gender equality share a theoretically justified consistency with divorce acceptance [Martin and Parshar 2006; Kapinus Flowers 2008]. To test this assumption, only data from the 2008 wave are used, because of the availability of the broadest set of countries and the battery of questions measuring attitudes towards gender roles. The comparative temporal trend will not be explored here because the composition of the gender-attitudes battery changed over time, which would make the comparison unreliable. The index of attitudes towards gender roles ${ }^{11}$ is used as the individual-level correlate for divorce accept-

11 The wording of the questions used for the index was:

1. A working mother can establish just as warm and secure a relationship with her children as a mother who does not work

2. A pre-school child is likely to suffer if his or her mother works

3. A job is alright but what most women really want is a home and children

4. Being a housewife is just as fulfilling as working for pay

5. Having a job is the best way for a woman to be an independent person

6. Both the husband and wife should contribute to household income

7. In general, fathers are as well suited to look after their children as mothers

8. Men should take as much responsibility as women for the home and children.

All of the items were rated on a 4-point Likert-type scale of agreement/disagreement. The index has the same range of values (1-4), where the higher value indicates egalitarian attitudes. Several items ( 1 and 5 to 8 ) have been reversed in order to get the same meaning. The gender index has some known problems [Lomazzi 2017] as it does not reach the recommended level of reliability (measured by Cronbach alpha $=0.586$ and splitting into three dimensions in factor analysis. Despite these known issues, it is an instrument frequently used to indicate gender attitudes. The mean value of the index ranges from 2.62 in Turkey to 3.32 in Norway. The overall mean is 2.87, which indicates a higher preference for egalitarian attitudes. 
Sociologický časopis/Czech Sociological Review, 2020, Vol. 56, No. 6

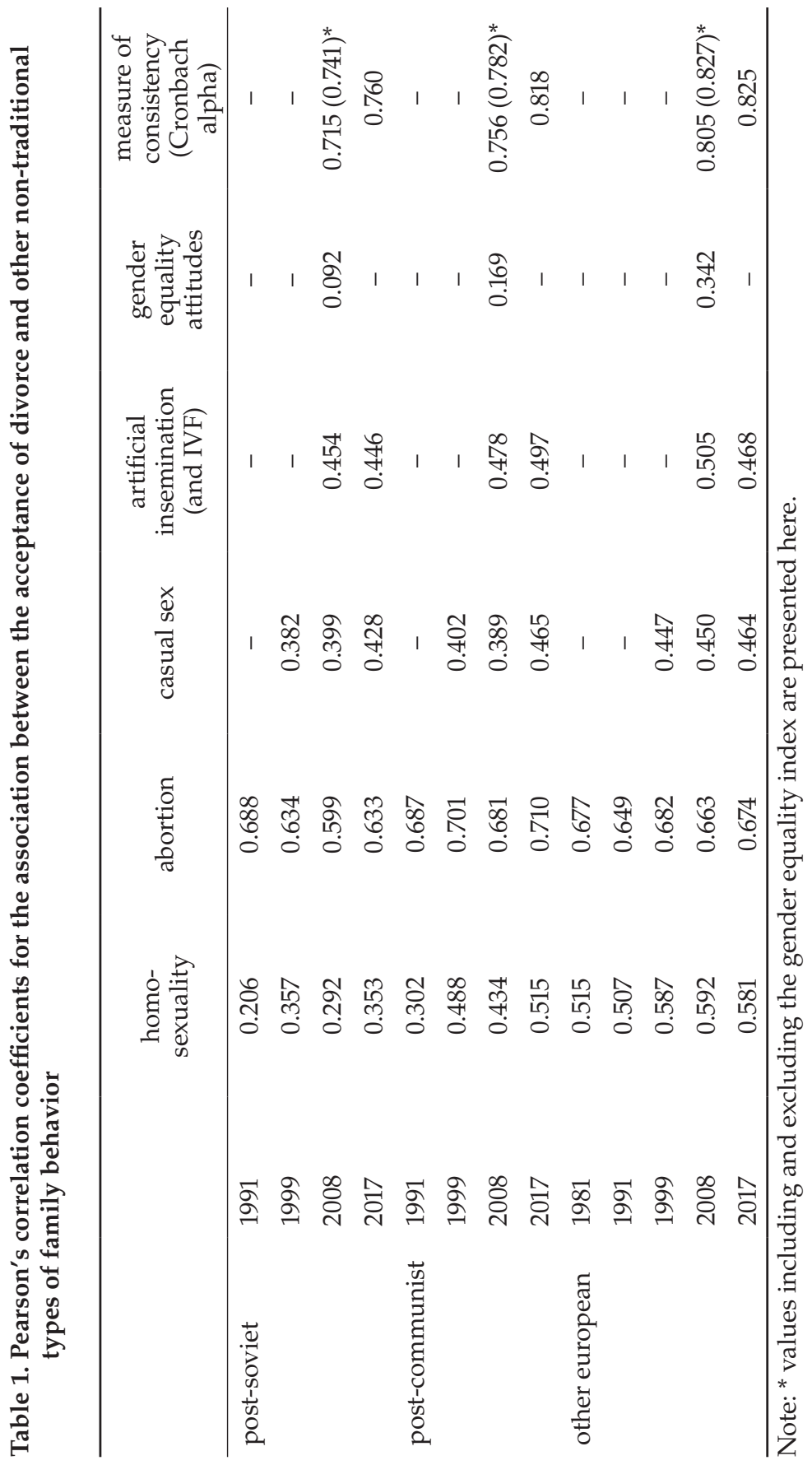


Figure 3. Association between the index of gender role attitudes and the divorce acceptance in aggregated data

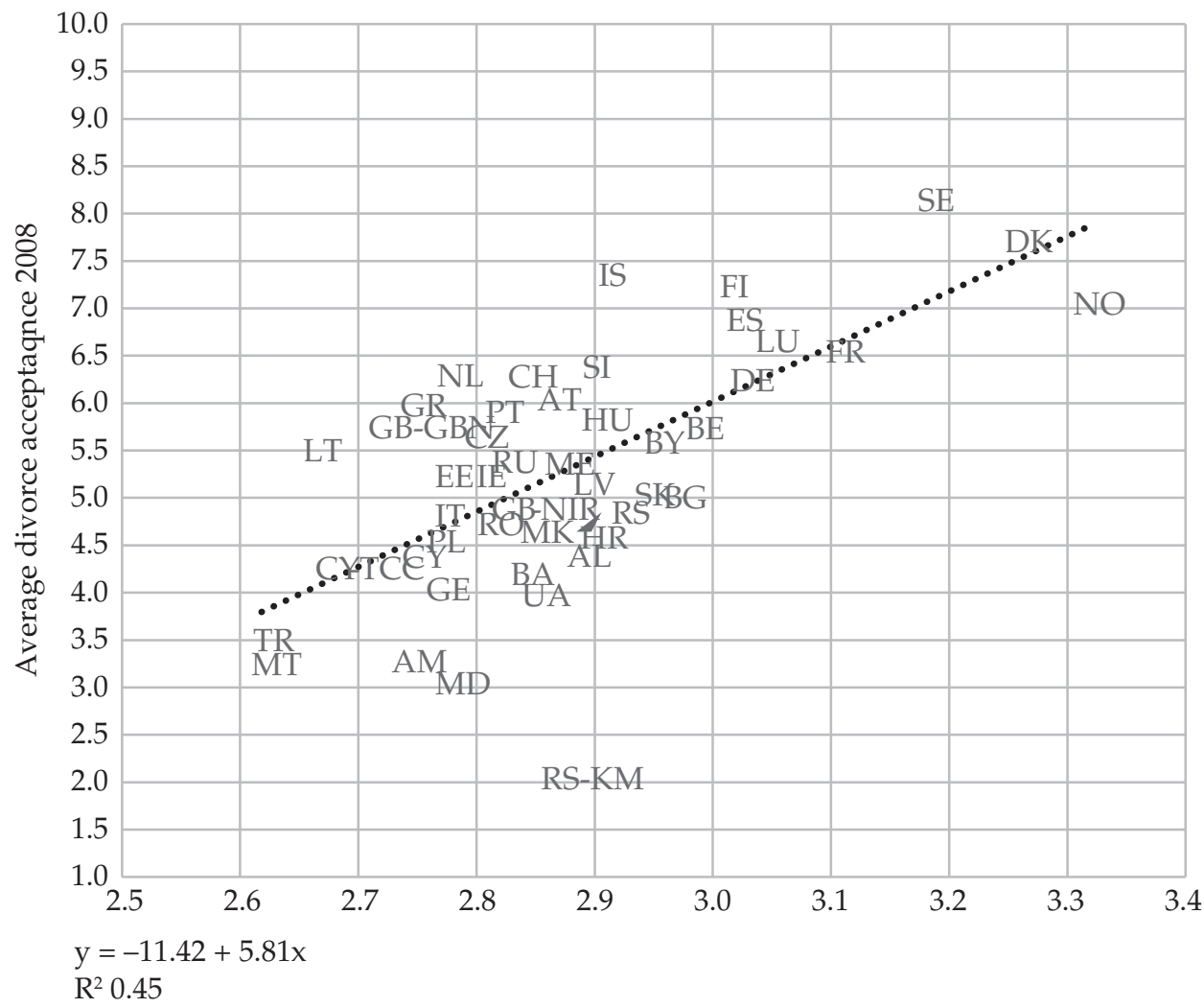

ance and the aggregated index at the country level is used as the measure for a macrostructural correlate of societal acceptance of divorce. The analysis shows that the mutual contingency of these two concepts at the individual level is consistently positive in all countries but varies significantly between the clusters (see Table 1). The weakest correlation is seen in the post-Soviet countries ( $R$ about 0.09 ) and Turkey. A slightly stronger association can be seen in the post-communist set of countries ( $R$ about 0.17 ) and the strongest correlation is found in the countries of western Europe ( $\mathrm{R}$ about 0.34 ). The contingency between these two concepts is clearly visible at the national level and indicates that more open divorce attitudes are found in countries where gender attitudes are prevailingly egalitarian (See Figure 3). For the last two waves in which the structure of indicators used is comparable, a measure of internal consistency (Cronbach's alpha) was used that helps to summarise the interdependency of the given set of value indicators. 


\section{Individual correlates of the acceptance of divorce}

In the latest waves of the EVS, the acceptance of divorce is almost the same among men and women, with slightly more positive attitudes towards divorce among women in nearly all countries. The acceptance of divorce is found to be considerably higher among women than men only in Serbia, Poland, Romania, and Switzerland, where the difference on the 10-point scale exceeds 0.4 points. This picture was different in the 1981 and 1990 rounds. In these data, we found a reversed pattern: a slight but systematically higher level of divorce acceptance among men. In the 1981 data, this could have been due to the smaller and more homogeneous set of participating countries, but the same figure is found in the 1990 survey, when the number of countries involved in EVS almost doubled. The tiny pattern of gender difference reversed around the beginning of the 21st century.

As the acceptance of divorce in the public discourse represents a decline in traditional family values, it is no surprise that these attitudes are considerably structured by the age of respondents. Across all the EVS waves and countries, there is a pattern of a negative age gradient of divorce acceptance (See Figure 4). This pattern has changed considerably over time as the differences across the age categories have been slowly decreasing during the forty years of the EVS.

Generally, the age differences were never as large as might be expected on the basis of knowledge about the trend of growing divorce acceptance during the EVS wave. This means that the shift in the general societal acceptance of divorce cannot simply be explained by the generational exchange. The international data in a longitudinal perspective show the mean values of about 5.6 for the two youngest cohorts (15-24, 25-34) in 1981. During the 1990s, the averages shifted towards 5.8 for the same cohorts (25-44 in the 1990 wave and 35-54 in the 1999 wave). In the last wave, the average was between 6 and 6.5 for the two oldest cohorts.

Looking at the data cross-sectionally, the sharpest generational differences were during the 1980s and 1990s, when younger respondents showed a much higher level of divorce acceptance than older respondents (a difference of about 1.9 points on the 10-point scale). ${ }^{12}$ In 2017, the differences between the oldest and youngest age groups in most countries are well below one point on the 10-point scale. The shift in the mean scores from rounds $1 / 2$ to round 5 was about two points in general, and the time span between 1981/1991 to 2017 it corresponds to movement between the stage in the life course that a person is at around age $20 / 30$ to the one a person is in at around age 60 .

Categorised education levels are only available in the integrated datasets beginning from the 1999 wave. Earlier integrated files only contain information on the age at which respondents completed their education; this information is available for all EVS waves. Therefore, the analysis first worked with the cardinal ${ }^{12}$ These results are limited only to the narrow group of western European countries that
participated in the initial EVS wave. 


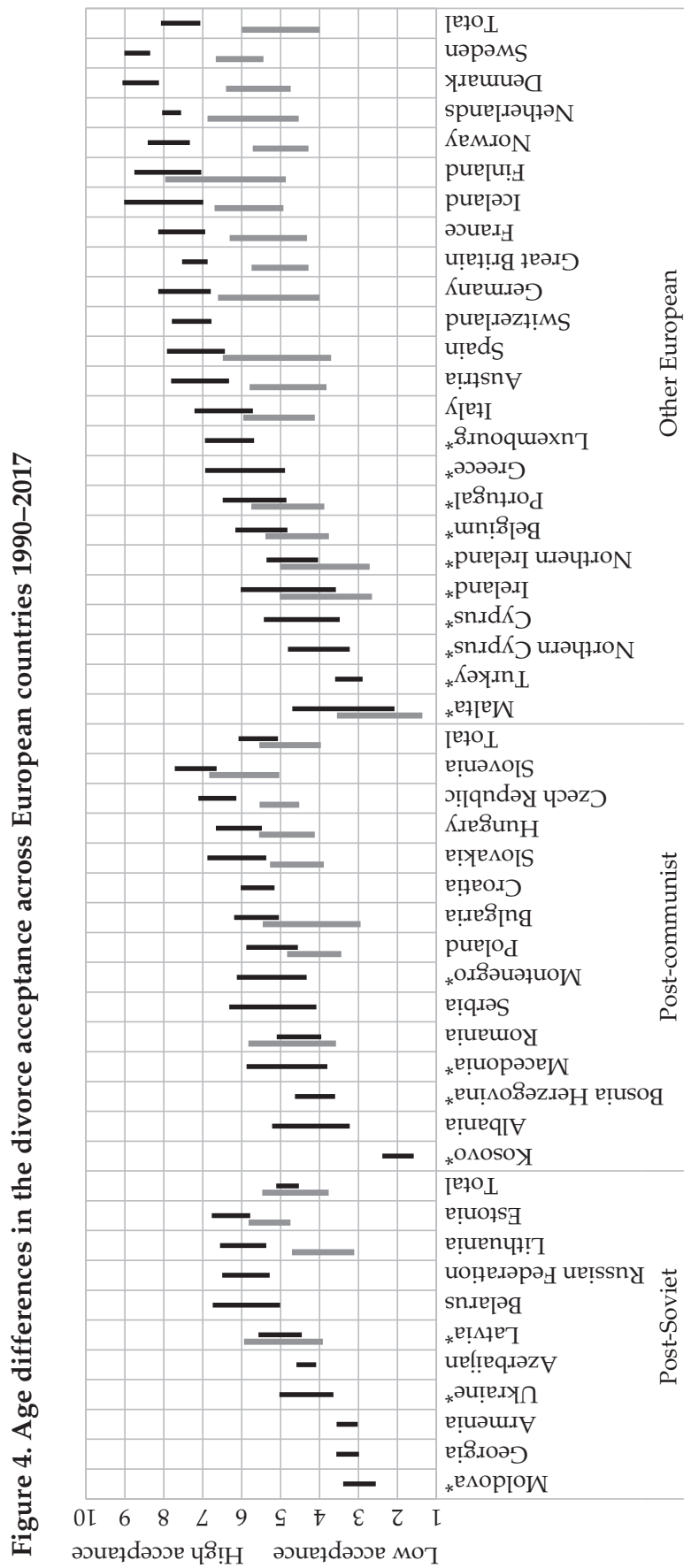




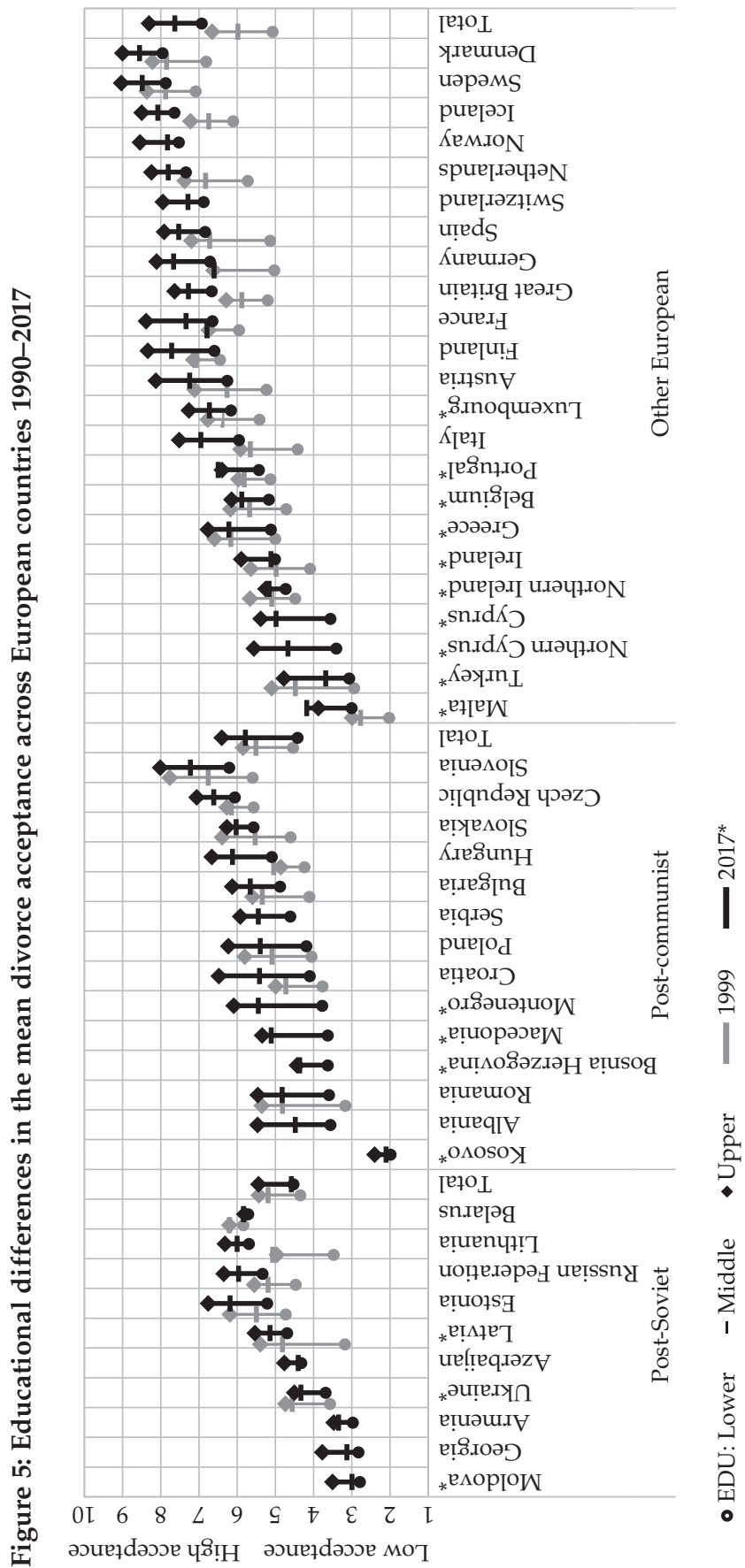


variable of the length of education in order to be able to compare trends in the association over the longest possible window of time, and then using the categories available for the 1999-2017 data in order to compare divorce acceptance across the categories of education level. Both analyses provide consistent results.

The correlation between years of schooling and divorce acceptance, as measured by Spearman's correlation coefficient, is positive in all the countries in all waves of the EVS. These results indicate a positive educational gradient of divorce acceptance, which means more educated respondents are more open to accepting divorce. The same conclusion can be reached by comparing the mean values of the scale of divorce acceptance across the three education categories available in the rounds 1999, 2008, 2017 (see Figure 5). The general pattern of a higher acceptance of divorce among more educated people holds across Europe, but its strength is very heterogeneous. Ranking the countries according to the relative difference in the mean level of divorce acceptance across educational categories shows a cumulation of former post-Soviet countries in the bottom part of the ladder, which means education levels have a weak effect on divorce acceptance in these countries (and divorce acceptance is generally lower here). In almost all of the countries that were not in the past part of the Soviet Union, the effect of education on divorce acceptance was found to be stronger. ${ }^{13}$ Compared to the previous demographic indicators examined, education level seems to have more persistent consequences for a person's attitude towards divorce: there was no general or systematic narrowing of the gap between the attitudes of different educational categories. This would be particularly interesting to compare with the weakening of the positive education gradient of divorce or its reversal in some European countries [Harkonen and Dronkers 2006; Matysyak, Styrc and Vignoli 2014], suggesting a discrepancy between the lower openness of the loweducated to divorce and the average or higher risk of divorce in these categories.

As family law was the domain of Christian doctrine for over a millennium, it is clear that acceptance of divorce will be affected by religion at a personal level, as well as by the proportion of religious people in the society, indicating the societal relevance of religion. We attempted to compare the differences in the influence of religion on divorce acceptance across European countries and across time. Starting at the individual level, the question on personal religion ${ }^{14}$ is used in a dichotomous way to compare the acceptance of divorce between selfdefined religious and non-religious respondents (see Figure 6). The differences are relatively smaller in the former post-Soviet countries, spanning from zero to 0.6 points on the scale. This is the only distinguishable cluster; the rest of the countries are mixed according to historical experience, economic level, or the pre-

\footnotetext{
13 The only exceptions were Finland and Northern Ireland.

${ }^{14}$ Independently of whether you go to church or not, would you say you are? - a religious person/ not a religious person/a confirmed atheist. Because of the small number of confirmed atheists in some countries, the latter two categories were merged.
} 


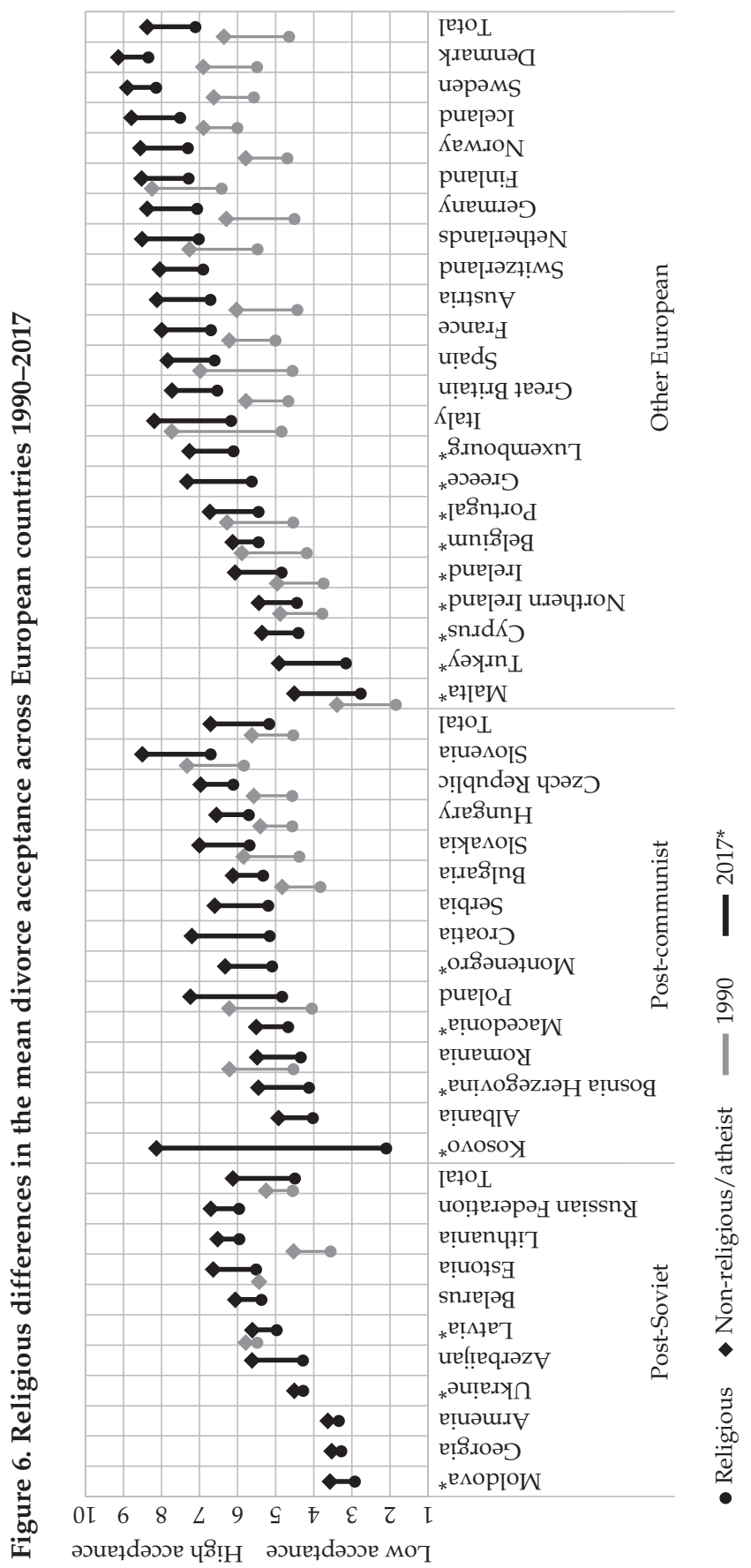


dominant religious denomination. Among the countries that participated in at least three EVS waves, the trend in the gap between religious and non-religious respondents was examined, but the results are not convincing.

\section{Summarising the divorce acceptance correlates in the regression model}

For a comprehensive model estimating individual attitudes towards divorce, a linear regression model was used that contained variables on respondents' characteristics - sex, age, education ${ }^{15}$, religion - and the year of data collection, and two contextual variables - country type (with three categories: post-Soviet, post-communist, and other) and the crude divorce rate. ${ }^{16}$ The dependent variable is the 10-point scale on the justification of divorce.

The model was built in two times three variants with identical variables, but selectively for three clusters of countries - post-Soviet, post-communist, and other. ${ }^{17}$ For each cluster the main effects of the variables were modelled and then the interactions of all of them with the EVS wave were added. The aim in doing so is to explore the trends in the effects of the explanatory variables across three decades in the case of the eastern countries and four decades in the case of most of the western countries. The geographical variance is explored by the modelling inside these clusters, but in order to keep the models comprehensible a country variable was not included, as here we are only interested in the distinctions between given clusters. Although the other countries cluster is rather heterogeneous and and across the various geopolitical criteria some other division might exist, I decided to focus on a comparison between the two sets of countries with a communist history on the one hand and the rest of the Europe with mostly similar democratic post-war development in the second half of the 20th century on the other.

Three models estimating the main effects of given variables (marked as the 'A' models in Table 2) on divorce acceptance show the effects of gender to be relatively small, with men holding slightly more reserved attitudes towards divorce across all the country clusters. The models reveal that religion is of relatively high importance for personal attitude towards divorce and the effect of religion

\footnotetext{
${ }^{15}$ Because of the unavailability of categorised education in five EVS waves, we used the age at which school attendance was completed.

16 The crude divorce rate was obtained from the Eurostat database for the particular years in which EVS data collection took place in the given countries. In several exceptions where the data were not available from Eurostat, data were sought in the national statistical offices. If a country had no divorce records in a given year, it was dropped from the analysis of this model.

${ }_{17}$ All the available valid data for each cluster were used: the 1991-2017 waves for the postSoviet countries, $\mathrm{N}$ valid $=26397$, the 1991-2017 waves for the post-communist countries, $\mathrm{N}$ valid $=45807$, and the $1981-2017$ waves for the other countries, $\mathrm{N}$ valid $=101473$.
} 
is very similar across the country clusters. The effect of education is more important outside the post-Soviet cluster. ${ }^{18}$ The most pronounced difference is in the temporal variable representing the EVS waves, because the rise of divorce acceptance is very diverse in these three clusters of countries. Because the crude divorce rate is the only macro-level variable used across the models, it is included in the individual-level modelling to keep the regression as simple as possible. Therefore, only the individual level effect is captured here, without the country-level variance (the country-level variance was analysed through the scatterplots - see Figure 2). The crude divorce rate is the second strongest effect in the model and it is slightly stronger in the countries outside the post-Soviet or post-communist cluster.

The models using interactions add the information about the temporal variations in the effects of the explanatory variables (marked as the ' $\mathrm{B}$ ' models in Table 2). Adding the interactions into the models substantially changed the model fit criteria ${ }^{19}$ and the parameters for the main effects. The importance of religiosity increased in the post-Soviet and post-communist cluster and the differentiated effect of the divorce rate was even more magnified.

The temporal trends the models captured suggest almost no changes in the effect of gender, except the narrowing of the difference between men and women in the western countries. The effect of religiosity declines over time in the postSoviet cluster, but the changes are only subtle in the other parts of Europe. The effect of age decreases in all countries, but only negligible trends can be observed in the effect of education. The reverse pattern is found in the case of the crude divorce rate's effect, which decreases over time in the post-Soviet cluster, shows no change in the group of post-communist countries, and increases in the group of other countries.

\section{Discussion and conclusion}

The acceptance of divorce is increasing in all the European countries that participate in the EVS, with only a few exceptions. Nonetheless, behind this general figure there are considerable differences in the distinctive clusters of countries. These clusters can be defined by the political history of the regions, which can be categorised as post-Soviet, post-communist, and other countries. The rise in divorce acceptance is weakest in the post-Soviet countries, modest in the post-

\footnotetext{
${ }^{18}$ When comparing the levels of parameters, it is necessary to consider the much higher range of the scales of age and years of schooling compared to gender, religiosity, and crude divorce rate.

${ }^{19}$ Comparing the AIC according to the formula exp $\left(\left(\mathrm{AIC}_{\min }-\mathrm{AIC}_{i}\right) / 2\right)$, the models containing interactions provide a fairly better estimation despite the expense of the higher number of parameters.
} 


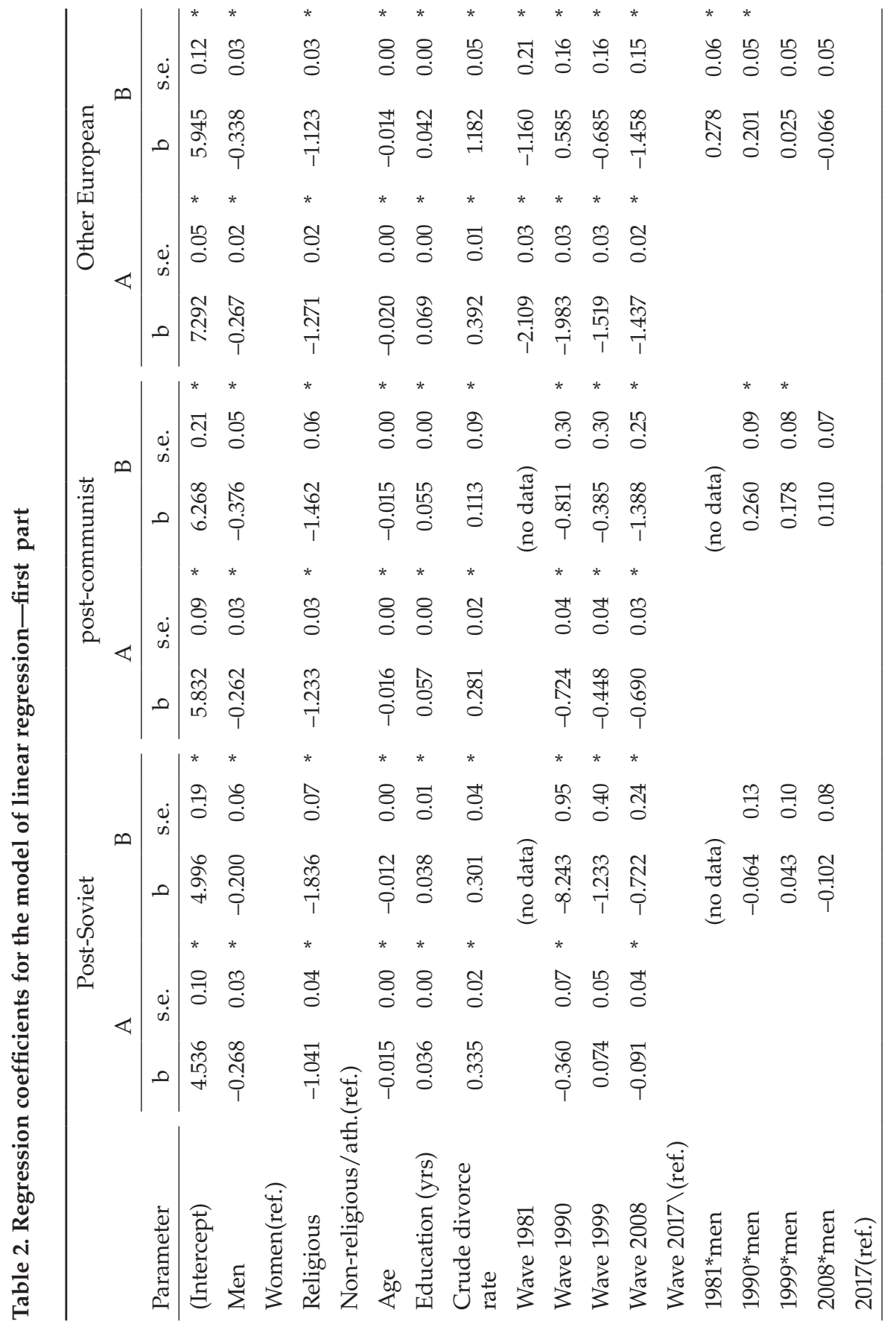




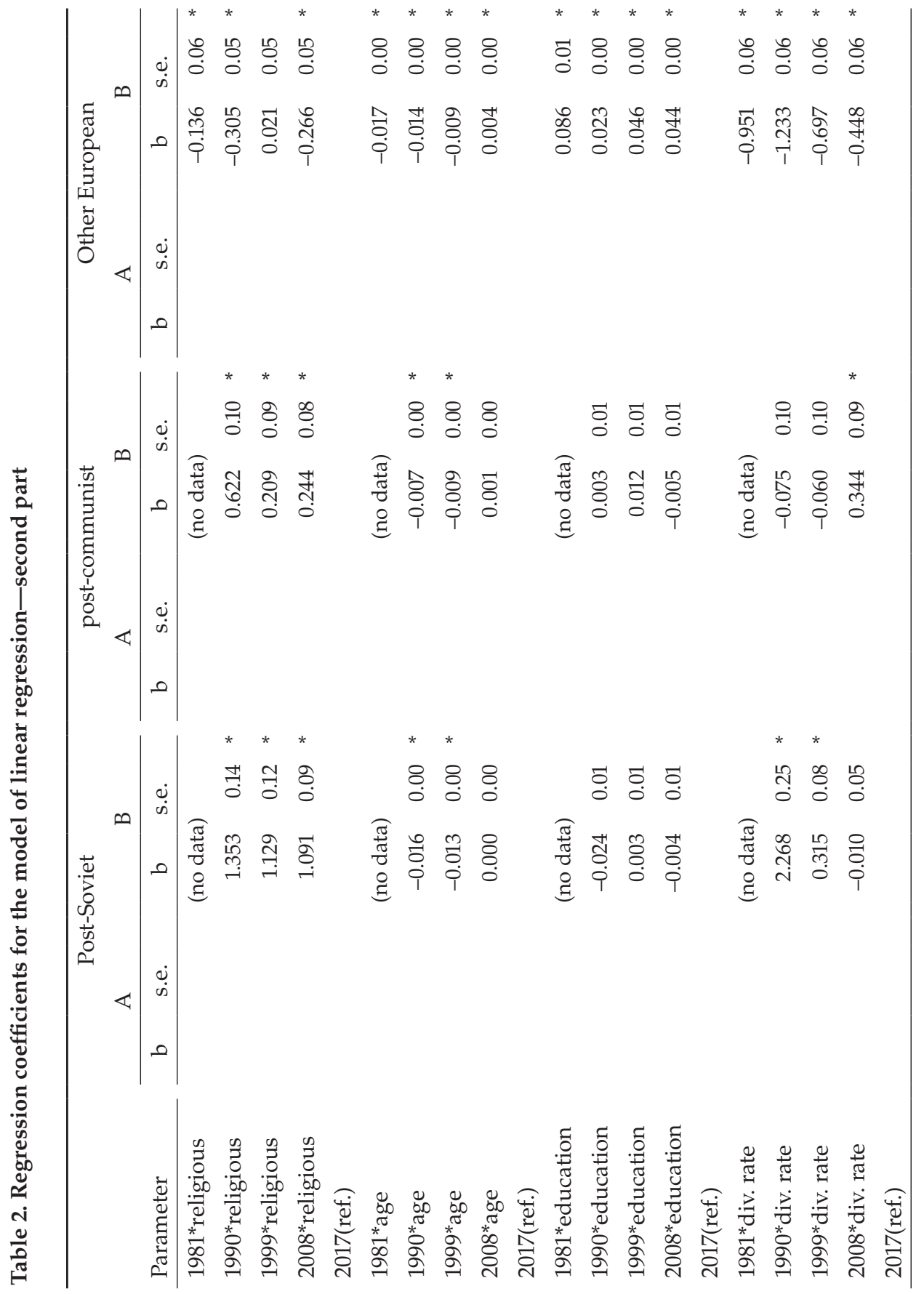


Articles

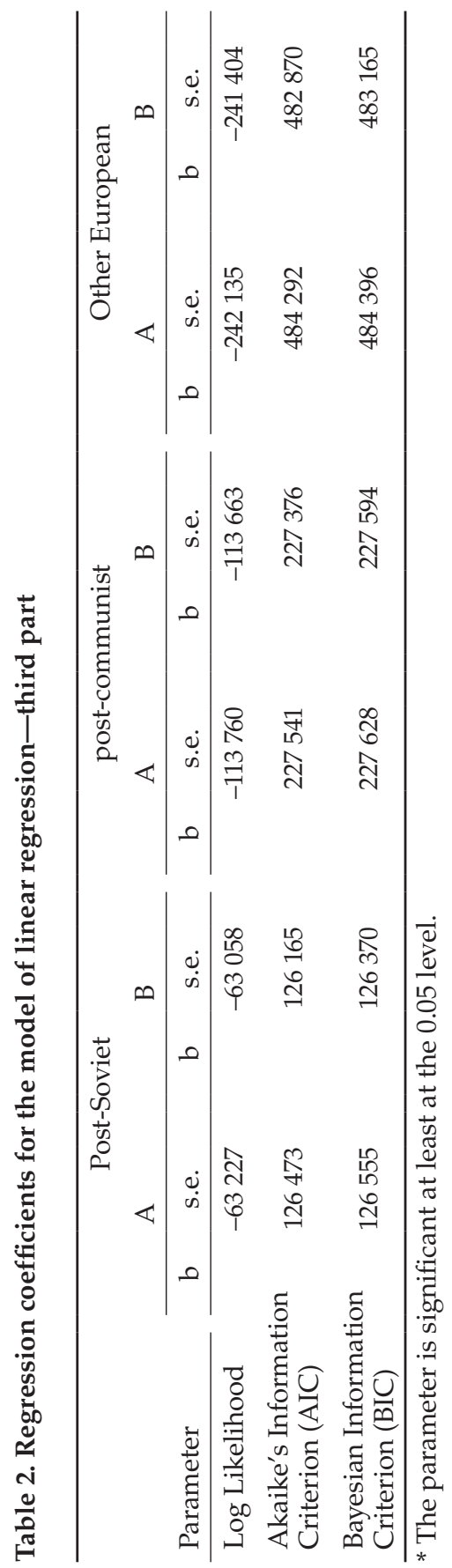


communist countries, and strongest in other European countries. These results are in line with our first hypothetical assumption, that divorce acceptance is rising, but there are different dynamics behind the increase in different geographical contexts. Despite of the fact that we tested several hypotheses about the relationship between divorce acceptance and the other concepts, the distinction of the clusters is the result of the inductive process of the data exploration, which reveals consistent patterns of dissimilarity between the three sets of countries. The clusters differ by the general levels and trends in divorce acceptance, but the most sociologically relevant differences were found in the role played by factors that correspond to divorce acceptance. This was also the main reason for the distinction between the post-Soviet and the post-communist countries. Even though the countries share a similar historical experience, the patterns of internal consistency between value orientations concerning family behaviour and its interdependencies with external factors are different. These dissimilarities could be the result of the different status of countries during the communist era (whether a country was a part of the Soviet Union vs a satellite of the union) or the result of different paths of societal development after the fall of communism and the dissolution of the Soviet Union. The post-Soviet countries mostly experienced more turbulent economic and social changes than the former satellite states.

The connection between divorce acceptance and divorce rates, tested in our second hypothesis, has an uneven shape on the aggregated level. Therefore, the relationship between divorce acceptance and divorce prevalence varies considerably between societies: Among the post-Soviet countries, the relatively low level of divorce acceptance is at odds with their relatively high divorce rates. Among the post-communist countries, divorce acceptance rises with divorce prevalence, but the acceptance is lower than in the western part of Europe. It is technically possible to consider two regression lines with a different slope and a lower intercept in the post-communist countries. The effect of the relative shift in divorce prevalence is smaller, and given the lower starting points in divorce acceptance it leads to relatively lower results in divorce acceptance in post-communist countries. Summarising these results, our second hypothesis cannot be rejected, but the empirical evidence for it is stronger among the western European societies.

Our third hypothesis focused on the consistency between divorce acceptance and attitudes towards other types of social action indicating non-traditional family behaviour (homosexuality, abortion, casual sex, artificial insemination) and attitudes towards gender roles. The analysis revealed a considerable level of consistency within this cluster of attitudes on the individual level. On the aggregated level the influence of gender attitudes was tested as well and the results show a significant correlation between the prevalence of egalitarian gender role attitudes and divorce acceptance.

The factors affecting divorce acceptance on an individual level have different effects in the different country clusters. Although the results showed divorce acceptance to be substantially structured by religion, education, and age (which 
fits with our fourth hypothesis), these effects are relatively weaker in the postSoviet and post-communist countries. The temporal persistence of the effects of religion and education is rather constant, but the negative effect of age weakens over time. Only weak empirical support was found for the influence of gender. When the effect of the aggregate measure of the divorce rate on individual divorce acceptance was tested, some very distinctive patterns were revealed: in the post-Soviet cluster the effect of the divorce rate weakened over time, no substantially important trend is observed in the post-communist countries, and the effect of the divorce rate increased over time in the other European countries.

The analysis is partly limited by data availability and partly by the necessary reduction of the complexity of the explored relationships. The available data map divorce acceptance on the subjective scale, which can be affected by social desirability in different ways in different societies - if public opinion tends towards openness, respondents may feel it unpleasant to go against the majority and vice versa. This effect can slightly homogenise the data. Furthermore, the data provide only a limited possibility to compare the trends in divorce acceptance in central and eastern Europe before 1999; therefore, we cannot consider the early stages of the (post-communist) transformation of society or the initial stage before the fall of the communist regimes. This could be the reason why the dynamics of divorce acceptance seem modest here throughout the surveyed period (although the same time intervals were compared, we cannot rule out the possibility that major changes may have occurred earlier on, outside the surveyed period). The need to reduce complexity led to an exploratory strategy being preferred that was based on descriptive statistics and only limited use of regression modelling. As the focus is mainly on comparisons between larger geo-political units defined by different political histories in the second half of the 20th century, a multilevel approach was omitted and the focus was placed on the models comparing three clusters of countries identified from an interpretation of compared descriptive statistics. Variability within the clusters is still present and cannot be ignored when interpreting the results, but the clustering helps to describe the general patterns in the data.

Thirty years after the fall of communism and the dissolution of the Soviet Union, the traces of those times are still present in the different normative and value systems in society. The communist regimes invested considerable effort in constructing a propagandistic image of a happy and healthy family. ${ }^{20}$ The revival of traditionalist family values that occurred in almost all western societies after the Second World World War was prolonged by the communist regime until it collapsed. After the late 1960s, the rest of Europe slowly changed the cultural frame of the institution of the family. Demographic profiles converged rapidly during the 1990s, when the traditional image of the family changed at a slower

${ }^{20}$ The concept of 'push into the family' depicts the consequences of this effort: if there is an offer of a relatively stable family life, involvement in the public sphere will be weaker. 
tempo or remained unchanged in the eastern part of Europe. The acceptance of divorce represents only one aspect of this consistent cluster of values. The analysis here showed that the acceptance of divorce is consistent with the acceptance of homosexuality, abortion, and artificial insemination as well as with traditional gender role assignment on the societal level. This traditional value system would be functional if the reality of demographic behaviour matched the image of a traditional family, but the opposite is true. Many post-communist and post-Soviet societies face the high prevalence of divorce, non-marital births and decreasing marriage rates as well as the other European countries, even more in some cases [Eurostat 2020a, 2020b, 2020c]. This is a particularly important message for the discussion on the conceptual frame of the second demographic transition in the post-Soviet and post-communist contexts. Although the analyses do not allow for causal explanations, a logical interpretation of the results seems to support the argument against SDT: value changes did not precede changes in demographic behaviour in these geopolitical regions. The conjunction of postmodern demographic behaviour and lingering traditional family values creates a field of social conflict that yields specific dimensions of pathology connected to non-traditional types of behaviour. The post-Soviet context is also characterised by a connection between the traditional-family discourse with the agenda of the Orthodox Church. If the societal image of divorce is associated with sin, failure, child deprivation, infidelity, or even violence, these cultural meanings will to some extent shape the experience of people who have divorced and the social environment's attitudes towards them. These mechanisms can constitute difficulties in individuals' ability to recover from divorce and can also complicate court proceedings and negotiations on post-divorce arrangements. As demographic figures tend to converge (at least when it comes to generally high divorce rates and unstable informal relationships), we may also expect a convergence of value systems in the future. On the other side, family change in the post-communist and post-Soviet context is partially framed as a western cultural import (with the example of gender-related or LGBTI issues being a prominent topic of fake news on western decadence). One of the implications for further research is to capture the cultural context of the expected convergence between demographic behaviour and value systems.

PetR FuČíK is an assistant professor in the Department of Sociology, Faculty of Social studies, Masaryk University in the Czech Republic. His research focuses on post-divorce adaptation processes in connection to social reproduction, stratification, and gender top$i$ cs. 


\section{References}

Afifi, T. D., S. Davis, A. Denes and A. Merrill. 2013. 'Analyzing Divorce from Cultural and Network Approaches.' Journal of Family Studies 19 (3): 240-253, https://doi.org/10.5172/jfs.2013.19.3.240.

Amato, P. R. 1988. 'Parental Divorce and Attitudes toward Marriage and Family Life.' Journal of Marriage and the Family 50 (2): 453-461, https://doi.org/10.2307/352010.

Amato, P. R. and A. Booth. 1991. 'The Consequences of Divorce for Attitudes toward Divorce and Gender Roles.' Journal of Family Issues 12 (3): 306-322, https://doi.org/10.1177/019251391012003004.

Amato, P. R. and S. Irving. 2005. 'Historical Trends in Divorce in the United States.' Pp. ?-? in Handbook of Divorce and Relationship Dissolution, edited by M. A. Fine and J. H. Harvey. Abingdon: Routledge.

Bauman, Z. 2003. Liquid Love: On the Frailty of Human Bonds. Cambridge, UK: Polity Press.

Becker, G. S. 1981. A Treatise on the Family. Cambridge, MA: Harvard University Press.

Beck, U. and E. Beck-Gernsheim. 2005. Individualization: Institutionalized Individualism and Its Social and Political Consequences. London: Sage Publications.

Cherlin, A. J. 2004. 'The Deinstitutionalization of American Marriage.' Journal of Marriage and Family 66 (4): 848-861, https://doi.org/10.1111/j.0022-2445.2004.00058.x.

Cherlin, A. J. 2009. 'The Origins of the Ambivalent Acceptance of Divorce.' Journal of Marriage and Family 71 (2): 226-229, https://doi.org/10.1111/j.1741-3737.2009.00593.x.

Cherlin, A. J. 2020. 'Degrees of Change: An Assessment of the Deinstitutionalization of Marriage Thesis.' Family Relations 82: 62-80, https://doi.org/10.1111/jomf.12605.

Cooke, L. P. et. al. 2013. 'Labor and Love: Wives' Employment and Divorce Risk in its Socio-Political Context.' Social Politics 0 (0): 1-28, https://doi.org/10.1093/sp/jxt016.

Coontz, S. 2007. 'The Origins of Modern Divorce.' Family Process 46 (1): 7-16, https://doi.org/10.1111/j.1545-5300.2006.00188.x.

Coontz, S. 2015. 'Revolution in Intimate Life and Relationships.' Journal of Family Theory and Review 7 (1): 5-12, https://doi.org/10.1111/jftr.12061.

Emery, R. E. 2013. Cultural Sociology of Divorce: An Encyclopedia. Thousand Oaks, CA: Sage, https://doi.org/10.4135/9781452274447.

Eurostat. 2020a. 'Divorce Indicators.' Retrieved 13 November 2020 (https://ec.europa.eu/eurostat/data/database).

Eurostat. 2020b. 'Fertility.' Retrieved 13 November 2020 (https://ec.europa.eu/eurostat/data/database).

Eurostat. 2020c. 'Marriage and Divorce.' Retrieved 13 November 2020 (https://ec.europa.eu/eurostat/data/database).

Furtado, D., M. Marcén and A. Sevilla. 2011. 'Does Culture Affect Divorce Decisions? Evidence from European Immigrants in the US.' IZA Discussion Papers No. 5960. Bonn: Institute of Labor Economics (IZA).

Gedeshi, I., P. M. Zulehner, D. Rotman, L. Titarenko, J. Billiet, K. Dobbelaere, J. Kerkhofs, et al. 2015. 'European Values Study Longitudinal Data File 1981-2008 (EVS 1981-2008).' GESIS Datenarchiv, Köln. ZA4804 Datenfile Version 3.0.0 (2015), doi:10.4232/1.12253.

Gerstel, N. 1987. 'Divorce and Stigma.' Social Problems 34 (2): 172-186, https://doi.org/10.2307/800714.

Gerstel, N. 1988. 'Divorce, Gender, and Social Integration.' Gender and Society 2 (3): 343-367, https://doi.org/10.1177/089124388002003007.

Hackstaff, K. B. 1999. Marriage in a Culture of Divorce. Philadelphia, PA: Temple University Press. 
Hajnal, J. 1965. 'European Marriage Patterns in Perspective.' Pp. 101-143 in Population in History. Essays in Historical Demography, edited by D. V. Glass and D. E. C. Eversley. London: Edward Arnold.

Härkönen, J. and J. Dronkers. 2006. 'Stability and Change in the Educational Gradient of Divorce. A Comparison of Seventeen Countries.' European Sociological Review 22 (5): 501-517, https://doi.org/10.1093/esr/jcl011.

Hiller, V. and M. Recoules. 2010. 'Divorce Decisions, Divorce Laws and Social Norms.' Documents de travail du Centre d'Economie de la Sorbonne 10046. Paris: Université Panthéon-Sorbonne (Paris 1), Centre d’Economie de la Sorbonne.

Inglehart, R. and W. E. Baker. 2000. 'Modernization, Cultural Change, and the Persistence of Traditional Values.' American Sociological Review 65 (1): 19-51, https://doi.org/10.2307/2657288.

Inglehart, R. and C. Welzel, C. 2005. Modernization, Cultural Change, and Democracy: The Human Development Sequence. Cambridge: Cambridge University Press.

Kalmijn, M. and W. Uunk. 2007. 'Regional Value Differences in Europe and the Social Consequences of Divorce: A Test of the Stigmatization Hypothesis.' Social Science Research 36 (2): 447-468.

Kapinus, C.A. and D. R. Flowers. 2008. 'An Examination of Gender Differences in Attitudes toward Divorce.' Journal of Divorce E Remarriage 49 (3-4): 239-257, https://doi.org/10.1080/10502550802222469.

Konstam, V., S. Karwin, T. Curran, M. Lyons and S. Celen-Demirtas. 2016. 'Stigma and Divorce: A Relevant Lens for Emerging and Young Adult Women?' Journal of Divorce $\mathcal{E}$ Remarriage 57 (3): 173-194, https://doi.org/10.1080/10502556.2016.1150149.

Lesthaege, R. 2014. 'The Second Demographic Transition: A Concise Overview of Its Development.' Proceedings of the National Academy of Sciences 111 (51): 18112-18115, https://doi.org/10.1073/pnas.1420441111.

Lomazzi, V. 2017. 'Testing the Goodness of the EVS Gender Role Attitudes Scale.' Bulletin of Sociological Methodology/Bulletin de Méthodologie Sociologique 135(1): 90-100, https://doi.org/10.1177/0759106317710859.

Martin, S. P. and S. Parashar. 2006. 'Women's Changing Attitudes towards Divorce, 1974-2002: Evidence for an Educational Crossover.' Journal of Marriage and Family 68 (1): 29-40, https:// doi.org/10.1111/j.1741-3737.2006.00231.x.

Matysiak, A., M. Styrc and D. Vignoli. 2014. 'The Educational Gradient in Marital Disruption: A Meta-analysis of European Research Findings.' Population Studies 68 (2): 197-215, https:// doi.org/10.1080/00324728.2013.856459.

Schovanec, B. and C. Lee. 2001. 'Culture and Divorce.' Journal of Divorce E Remarriage 36 (1-2): 159-177, https://doi.org/10.1300/J087v36n01_09.

Sieben, I. and E. Verbakel. 2013. 'Permissiveness toward Divorce: The Influence of Divorce Experiences in Three Social Contexts.' European Sociological Review 29 (6): 1175-1188, https://doi.org/10.1093/esr/jct008.

Smyth, L. 2016. 'The Disorganized Family: Institutions, Practices and Normativity.' British Journal of Sociology 67 (4): 678-696, https://doi.org/10.1111/1468-4446.12217.

Sobotka, T. 2008. 'Overview Chapter 6: The Diverse Faces of the Second Demographic Transition in Europe.' Demographic Research 19 (8): 171-224, https://doi.org/10.4054/DemRes.2008.19.8.

Thornton, A. 1985. 'Changing Attitudes toward Separation and Divorce: Causes and Consequences.' American Journal of Sociology 90 (4): 856-872, https:// doi.org/10.1086/228147.

Thornton, A. and L. Young-DeMarco. 2001. 'Four Decades of Trends in Attitudes toward Family Issues in the United States: The 1960s through the 1990s.' Journal of Marriage and Family 63 (4): 1009-1037, https://doi.org/10.1111/j.1741-3737.2001.01009.x. 
Toth, K. and M. Kemmelmeier. 2009. 'Divorce Attitudes Around the World: Distinguishing the Impact of Culture on Evaluations and Attitude Structure.' Cross-Cultural Research 43 (3): 280-297, https://doi.org/10.1177/1069397109336648. van de Kaa, D. J. 1987. 'Europe's Second Demographic Transition.' Population Bulletin 42 (1): 1-59.

Whitehead, B. D. 1997. The Divorce Culture. New York: Alfred A. Knopf.

Wilkins, L. S. 2016. 'Secularization and the Wider Gap in Values and Personal Religiosity Between the Religious and Nonreligious.' Journal for the Scientific Study of Religion 55 (4): 717-736, https:// doi.org/10.1111/jssr.12307.

Wolfinger, N. H. 2005. Understanding the Divorce Cycle. Children of Divorce in Their Own Marriages. New York: Cambridge University Press, https://doi.org/10.1017/CBO9780511499616.

Yodanis, C. 2005. 'Divorce Culture and Marital Gender Equality: A Cross-National Study.' Gender \& Society 19 (5): 644-659, https://doi.org/10.1177/0891243205278166. 
